Int. J. Med. Surg. Sci.,

1(1):73-93, 2014.

\title{
Nanotechnology in Preclinical and Clinical Drug Development
}

\section{La Nanotecnología en el Desarrollo Preclínico y Clínico de Fármacos}

\author{
Cristian Vilos*,**
}

VILOS, C. Nanotechnology in preclinical and clinical drug development. Int. J. Med. Surg. Sci., 1(1):73-93, 2014.

SUMMARY: Nanotechnology is generating a strong impact in preclinical and clinical drug development. The diversity of current nanotechnologies offers a broad platform used to enhance the performance of drug discovery screening, to develop sensitive and specific methods used to unveil the mechanisms behind the actions of drugs, to determine the function and interaction between molecules, and to study the physiological and pathological changes of cellular components. In addition, advancements in nanobiotechnology have led to the design of new nanomaterial-based drug candidates that present a novel approach to medical diagnostics and therapeutics. The biocompatible nanoarchitecture of the marketed nanocarriers used for drug delivery has increased the solubility and effectiveness of classical drugs, and has provided the technology required for the targeted delivery of encapsulated tissue-organ specific therapeutics. Because of its effect on drug development, nanotechnology serves as the foundation for many future medical endeavors. This article provides an overview of the basics of nanobiotechnology, and discusses its applications in drug discovery, design, and delivery systems.

KEY WORDS: Nanotechnology; Nanobiotechnology; Drug development; Drug Delivery.

\section{INTRODUCTION}

As an applied science that opens a world of creative possibilities, impacts almost all industries and areas of society, and contributes to significant global economic growth, nanotechnology has been compared to the industrial revolution of the 21st century (Yih \& Moudgi, 2007). The term nanotechnology refers to the manufacturing and utilization of materials, devices, and systems in the 0.1-100 nm dimension range $(1 \mathrm{~nm}=10-9 \mathrm{~m})$ (Riehemann et al., 2009). According to the US National Nanotechnology Initiative, "Nanotechnology is the understanding and control of matter that involves imaging, measuring, modeling, and manipulating matter at nanoscale, where unique phenomena enable novel applications". (Initiative, 2009). Nanotechnology, in practical terms, concerns the design and development of unique nanostructures that have improved the efficiency of industrial processes and promoted development in fields such as energy (Bruce et al., 2008), the environment (Mao \& Chen, 2007), materials (Obare \& Meyer, 2004), and medicine (Jain, 2008). Given the broad platform of applications that nanotechnology offers in life sciences, and the inherent nanoscale functions of the biological mechanisms that form living cells, nanobiotechnology has been an emerging research domain in nanotechnology. Nanobiotechnology has been pivotal to many significant advances in the methods currently used for diagnostics, biomedical imaging (Carmode et al., 2009), biosensors, drug delivery systems, etc. (Farokhzad, 2008).

\footnotetext{
Universidad Andres Bello, Facultad de Medicina, Center for Integrative Medicine and Innovative Science (CIMIS), Echaurren 183, Santiago, Chile

** Centro para el Desarrollo de la Nanociencia y Nanotecnología, Universidad de Santiago de Chile, Ecuador 3493, Santiago, Chile
} 
Through the use of highly specific and sensitive analytical tools like single-molecule force spectroscopy (Ros et al., 2004), nanoarrays (Wingren \& Borrebaeck, 2007), nanosensors (Vo-Dinh \& Kasili, 2005), and nanofluidics (Hong et al., 2009), nanobiotechnology has opened a new window in biomedical research. In addition, the application and rational design of nanostructures, like inorganic and metallic nanoparticles (Liong et al., 2008; Shi et al., 2009), dendrimers (Gillies \& Frechet, 2005), fullerenes (Djordjevic et al., 2006), and nanoparticles synthesized from biodegradable and biocompatible materials (Shi \& Huang, 2009), has enabled the development of sensitive methods used to detect molecular interactions, drug action mechanisms, and new diagnostic and therapeutic strategies that have positive impacts on drug development. These nanostructures have unique magnetic/optical properties (Zhao et al., 2006; Cruz Enriquez et al., 2008), better solubility (Alexis et al., 2008), and improved mechanical properties, such as strength and resistance in the case of polymers (Daniels et al., 1990; Pillai \& Panchagnula, 2001) at the nanoscale.

The discovery and development of new drugs for the prevention and treatment of disease is a long and costly course. From the synthesis of a new compound to marketing approval, the process of drug development takes approximately 14 years (Dimasi, 2001). It is estimated that by the year 2013 the cost to bring a potential drug to the end of Phase III trials will reach nearly $\$ 1.9$ billion dollars (DiMasi et al., 2003). Despite the advances in pharmacogenetics (Roses et al., 2008), proteomics (Walgren \& Thompson, 2004) and metabolomics (Morris \& Watkins, 2005) within the last decade, the number of FDA approvals for new molecular entities (NMEs) has unexpectedly decreased (Hughes, 2009). However, the application of nanotechnology in preclinical drug development has an increasingly important role because it provides more efficient methods to help researchers understand the relationship between cellular mechanisms and new potential drugs. Although there are a limited number of nanotechnology-based products available in the market at this point, these products have shown a strong impact in medicine.

Nanotechnology has facilitated the integration of different sciences and technologies and promises to be the main source for drug development in the future (Fig. 1). This article provides an overview of the basics of nanobiotechnology and discusses its applications in the discovery, design, and delivery of drugs.
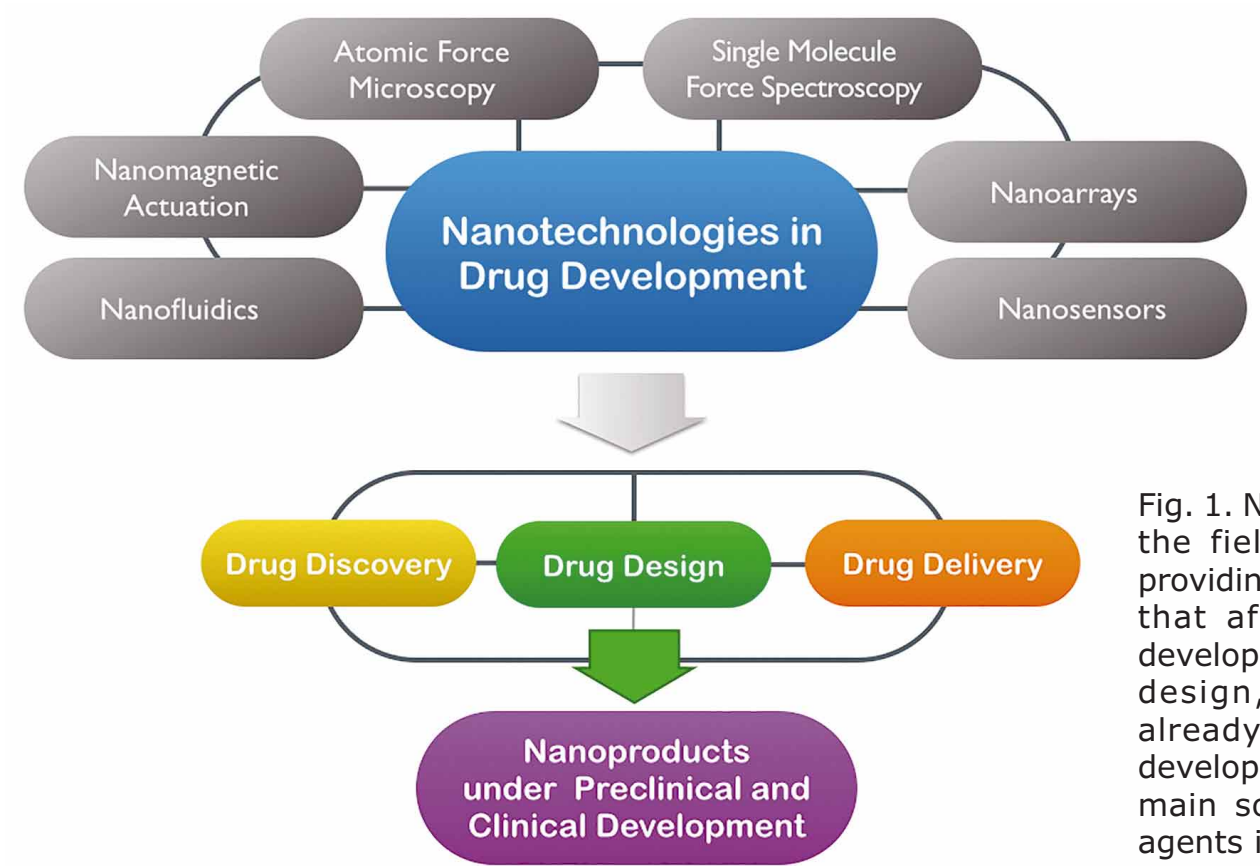

Fig. 1. Nanotechnology is impacting the field of life sciences and is providing a multifunctional platform that affects all phases of drug development. Drug discovery, drug design, and drug delivery are already crucial to improve drug development and promise to be a main source for new therapeutic agents in the near future. 


\section{Nanotechnologies in Drug Discovery.}

Drug discovery is the process of finding promising molecules with desired biological effects that have a potential for use as therapeutic drugs. It involves the knowledge of biological processes-molecular to physiological-and an understanding of disease in terms of gene expression, protein synthesis, and specific cellular and tissue responses. Nanobiotechnology has stimulated technological advances that have improved the effectiveness of drug development and has provided researchers with multiple tools to reach a better understanding of the specific actions of drugs, signaling pathways, and the cellular mechanisms of disease (Jain, 2005).

\section{Atomic Force Microscopy.}

Atomic force microscopy (AFM) is a multifunctional nanoscale tool that permits highresolution imaging with a high signal-to-noise ratio between biological macromolecules in their native environment. AFM also provides a sensitive approach to the manipulation of biomolecular machinery, and helps to understand the molecular relationship and function of cell structures (Edwardson \& Henderson, 2004). The principle of AFM is based on scanning with a tip on the sample surface to determine the interaction of forces between structures. This information is then digitalized from the signal acquired from the tip and converted into a three-dimensional image (Muller \& Dufrene, 2008). AFM allows for the observation of conformational changes of molecules in their native environment, such as protofilaments of microtubules induced by paclitaxel (Elie-Caille et al., 2007) and the role of actin filaments in the cytoskeletal elasticity of fibroblasts (Rotsch \& Radmacher, 2000). In addition, AFM has enabled the study of size distributions and transport of cellular vesicles (Kanno et al., 2002; Schonherr et al., 2004; Jin et al., 2006; Leonenko et al., 2000; Mitchell et al., 2007) and has permitted the analysis of molecular interactions between components of the extracellular matrix (i.e. fibronectin and heparine-like glicosaminoglycans) (Creutz \& Edwardson, 2009). Other significant applications have been the identification of the signaling mechanisms of proteins located throughout cellular membranes, as well as the study of the changing topography and dynamics of lipid bilayers as a result of the binding and insertion of proteins, drugs, and antimicrobial peptides (Oreopoulos \& Yip, 2009; Mingeot-Leclercq et al., 2008; Muller, 2006).

\section{Single-Molecule Force Spectroscopy.}

Single-molecule force spectroscopy (SMFS) is a newly developed AFM technique, and is an efficient analytical tool for the structural and functional investigation of single biomolecules in their native environments (Hinterdorfer \& Dufrene, 2006). The molecular interaction is the mechanism that governs all biological processes, and the affinity between the molecules is described as the net equilibrium between a bound and unbound state at zero force. SMFS indirectly determines the affinity between molecules, quantifying the mechanical properties of resistance to the applied force (Muller \& Dufrene; Mitchell et a/.). The application of SMFS involves the study of cell adhesion (Benoit et al., 2000; Garcia-Manyes et al., 2006) the mechanisms of folded and unfolded proteins (Sharma et al., 2007; Staple et al., 2008), compaction of eukaryotic DNA (Kruithof et al., 2009; Chien \& van Noort, 2009), and receptor-ligand interactions (Kersey et al., 2006; Gilbert et al., 2007). Shi et. al. (2009), determined the interaction between receptors ErbB (HER3/HER2), Herceptin, and Heregulin b1 (HRG) through SMFS. ErbB is a member of a family of epidermal growth factor receptors and is overexpressed in many cancers. HRG is a specific ligand of HER3, and Herceptin is an effective monoclonal antibody against HER2 approved by the FDA to treat breast cancer. The results showed that the presence of herceptin produces changes in the dynamic force spectrum of HRG-HER3/HER2 and HRG-HER3-increasing the binding rate of HRG-HER3 after the inhibition of HER2 through the administration of Herceptin. SMFS presents a sensitive method to study both the signaling and molecular mechanisms of antitumor drugs, and promises to have a significant impact on drug development.

\section{Nanomagnetic Actuation.}

Nanomagnetic actuation is an innovative tool that remotely manipulates cells, making it 
possible to study signal transduction (Mannix et al., 2008), cell adhesion, integrin clustering (Maheshwari et al., 2000), and the intracellular signaling associated with ion channels (Mannix et al.; Hughes et al., 2008). This concept integrates the use of magnetic nanobeads and a receptor, or an alternative biological compound, to stimulate the given environment. As a result, the application of nanomagnetic actuation has given rise to a greater understanding of transmembrane signal transduction pathways, elucidated the pathways that cause apoptosis, and initiated various developments in cellular analysis (Dobson, 2008). The use of nanomagnetic actuation in drug discovery presents a new approach to the study of nanoproduct functionality.

\section{Nanoarrays/Nanobiochips.}

A biochip is a collection of miniaturized spots arranged on a solid substrate that permits multiple tests to be performed simultaneously to achieve high-throughput screenings and is commonly referred to as a microarray (Rusmini et al., 2007). Microarrays are a useful and standard screening tool used to determine nucleic acid profile expressions and protein-protein interactions. With the development of nanotechnology, nanoarrays have come to represent the next stage in the evolution of microarrays (Chen \& Li, 2007). When compared with microarrays, nanoarrays work more efficiently on the nanoscale because they do not require large sample volumes, they allow for the measurement of interactions between individual molecules, and they provide a higher feature density (100-1,000 times) and sensitivity.

The development of nanoarray systems involves the application of tools and strategies used for detection of molecular interactions, such as single-molecule sandwich immunoassays, block copolymer templates, and nanobeadsprotein conjugates (Lee et al., 2009; Powell et al., 2009; Kumar et al., 2007). In addition, it is necessary to have a platform used to produce nanobiochips. Jung et al. (2009) described the synthesis of a bioplatform designed for the construction of nanobiochips from uniform gold nanodot arrays with a diameter of $60 \mathrm{~nm}$, which was synthesized using a nanoporous alumina mask < $500 \mathrm{~nm}$ in thickness by thermal evaporation method.

Advances in nanoarray technology have enabled the measurement of the isoelectric point of proteins through the combined use of Kelvin probe force microscopy (KPFM) and nanoarray systems (Sinensky \& Belcher, 2007). Nanoarray technology is a rapidly growing field and promises to advance drug discovery and the pharmaceutical industry.

\section{Nanofluidics.}

Nanofluidics implies an extreme reduction in the quantity of fluid analyte compared to standard methodologies and is generally defined as the study and application of liquid flow on a range of 1-100 nm (Eijkel, 2009). Nanofluidics applies natural scaling length to study molecules at the single-molecule level, and introduces a new platform for high-throughput biological screening (Hong et al.). One area of development in the field of nanofluidics is single molecule fluorescence detection. Single molecule fluorescence detection provides an increased signal-to-noise ratio and can measure binding kinetics, diffusion of molecules through lipid membranes, and multiple fluorescent labels in heterogeneous solutions (Mannion \& Craighead, 2007).

Nanofluidics has been used as a method to study the ion dispersion and separation through nanochannel chromatography and nanochannel electrophoresis (Xuan, 2008; De Leebeeck \& Sinton, 2006). Moreover, nanofluidics has been combined with carbon nanotubes to develop new research platforms like nanotube-vesicle networks (Goldberger et al., 2006; Karlsson et al., 2003). According to advancements in research, nanofluidics promises to be a new analytical platform for drug discovery and development in the near future.

\section{Nanosensors.}

Nanosensors have many potential uses in the field of drug discovery because of the broad range of nanostructures currently available. The nanoarchitecture of these sensors can be synthesized with unique and suitable physico- 
chemical properties according with their composition and corresponding functional groups, thus providing nanosensors with the ability to monitor and detect diseases and explore dynamic cellular metabolic processes. In addition, these nanomaterials have been combined with optical (Kneipp et al., 2009, electrochemical (Gau \& Wong, 2007), photochemical (Law et al., 2002), and magnetic (Solin, 2004) methods to understand sensor information and have allowed the imminent development of this field in nanotechnology.

Silicon nanowire has been used as a fieldeffect transistor device (FET) to monitor conductance and serves as a highly sensitive nanosensor and detector for $\mathrm{pH}$, and, biological and chemical species (Cui et al, 2001). It has also been used as a platform to detect the binding of small molecule inhibitors of ATP to $A B L$ (a protein tyrosine kinase responsible for chronic myelogenous leukemia). This strategy serves as an innovative tool used to distinguish the affinities between small molecules and has promoted the discovery of new drugs (Wang et al., 2005).

The detection and quantification of DNA through highly sensitive methods with low background noise is the key to enhancing biomedical research and the methods used for detection of genetic diseases. Recently, an approach to detect DNA through fluorescence resonance energy transfer (FRET) has been described where quantum dots (QDs) linked with DNA probes were used as agents to bind DNA targets and dye-labeled reporter strands were used as FRET donor acceptors. This method proved to be advantageous because the FRET signal was generated with less than $\sim 50$ copies per QD and elicited a near-zero background fluorescence (Zhang et al., 2005).

Surface Plasmon Resonance is an attribute of metal nanoparticles (i.e. Au and Ag) at a given size, shape, and dielectric environment (Haes \& Van Duyne, 2002). This property has provided inspiration for the design of several nanosensors that determine molecular interactions (Haes et al., 2005), binding kinetics (Ramakrishnan et al., 2009; Tamerler et al., 2006), dye absorbance spectra (Chen et al., 2002), and conformational changes of molecules (Chen, 2009).
In contrast, other studies using the "origami" method have produced an innovative three dimensional (3D) nanostructure based on self-assembly DNA box. This box $(42 \times 36 \times 36$ $\mathrm{nm} 3$ ) was characterized through cryogenic transmission electron microscopy, small-angle $X$-ray scattering, and AFM. These unique structures represent an excellent candidate that could be used as sensors for multiple DNA sequence signaling or utilized in a controlled drug release system given the controlled access to their interior compartment (Andersen et al., 2009).

\section{Nanotechnology in Drug Design.}

\section{Interactions of the Nano-Bio Interface.}

The understanding of biophysicochemical interactions between nanostructures and the biological interface is the key to the development of new strategies in nanoengineering and the synthesis of drug delivery systems. Nel et al. (2009), provided a complete overview of the main interactions at the nano-bio interface. Apart from the physicochemical dynamics, kinetics, and thermodynamic interactions, the main components of governance at the nanobio interface are the nanoparticle's physicochemical surface, the solid-liquid interface, and the nano-bio zone of contact.

The physicochemical surface is one of the most important factors when designing a drug delivery system that involves the direct administration of nanoparticles to the bloodstream. This is apparent because it is the surface that determines the nanoparticle's pharmacokinetic properties, system clearance time, biodistribution, and interactions with the complement, mononuclear phagocyte, hemostatic, fibrinolytic and other physiological systems. The physicochemical properties of the nanoparticle's surface that play a direct role in its functionality include: the chemical composition, shape and angle of curvature, porosity, surface crystallinity, heterogeneity, roughness, and hydrophobicity or hydrophilicity. In addition, the following attributes also dictate the rational design of new environment-specific nanostructures: surface charge, particle aggregation, state of dispersion, stability, biodegradability, dissolution characteristics, 
hydration, valence of the surface layer, and the characteristics of the suspending media. On the other hand, the solid-liquid interface, and the changes that occur when particles interact with the surrounding medium, is a very important aspect of nanoparticle design (Nel et al.; Baca et al., 2007). This solid-liquid interface is constantly subjected to dynamic and transient changes from van der Waals forces, electrostatic forces, and forces arising from charge, steric effects, as well as depletion and solvent interactions. In addition, the spatial localization of proteins, lipids, and glycosylated structures on the particle's surface will determine the nanobio zone of contact-a condition that ultimately influences targeting and cellular uptake properties (Nel et al.; Min et al., 2008).

\section{Nanomaterials-based Drug Candidates.}

An interesting development over the last few years has been the application of therapeutic nanostructures, such as carbon nanotubes, nanoshells, nanorods, and magnetic nanoparticles. Each of these nanosystems exhibits unique properties resulting from their magnetic and photothermal behavior and their overall structure. In addition to providing a noninvasive alternative to many medical procedures, systems that incorporate nanostructures have advantages that include reduced toxicity and improved biocompatibility. Nanomaterial-based drug candidates are an emerging therapeutic strategy in the realm of drug development that will have an important role in the medical field in the years to come.

\section{Carbon Nanotubes.}

Carbon nanotubes (CNTs) are perfectly cylindrical structures that can be classified as either single-walled nanotubes (SWNTs) or multiwalled nanotubes (MWNTs) (Martin \& Kohli, 2003). Their unique mechanical, electrical, and optical characteristics, combined with their physicochemical properties, enable covalent and non-covalent bonds between pharmaceutical entities, thus providing an innovative platform for the rational design of novel nanoscale constructs for drug development (Fig. 2) (Prato et al., 2008). In addition, it has been discovered that lipids can self-assemble and organize on the surface of sin-

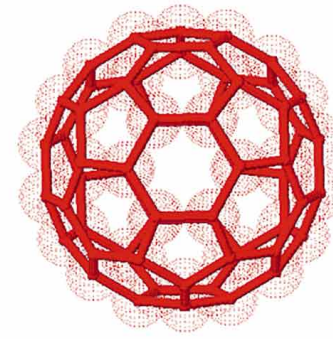

Fullerene

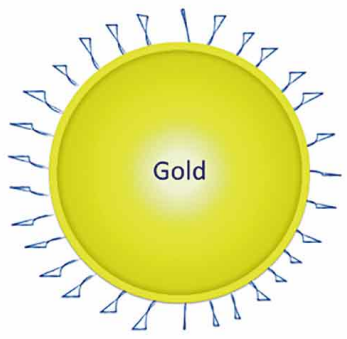

Gold

Nanoparticle

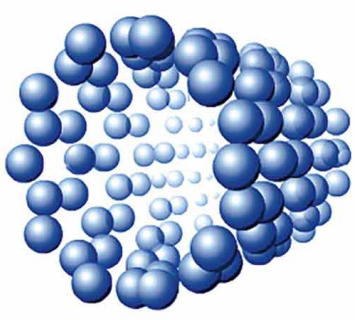

Carbon

Nanotube

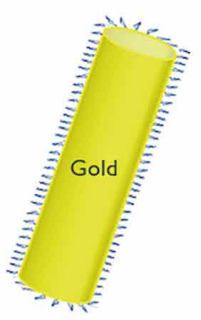

Nanorod

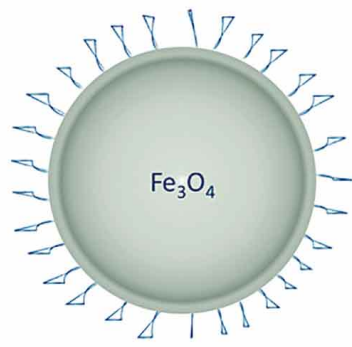

Magnetic

Nanoparticle

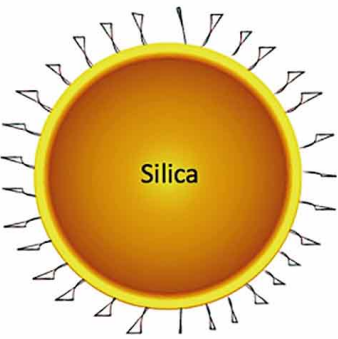

Nanoshell

Fig. 2. Advancements in nanotechnology have provided new nanoarchitectures that have lead to the design of new nanomaterial-based drug candidatespresenting a novel approach to medical therapeutics. 
gle-walled carbon nanotubes into regular ringshaped formations. Their polar surface and polymerized structure permits the attachment of soluble and stable particles in water in an environment lacking an excess of lipids or detergents. The advantage of using carbon nanotubes, in comparison to conventional micelles or vesicles, is that the carbon chains of the lipids of these structures are able to retain hydrophobic molecules of various sizes (Thauvin et al., 2008). It has also been determined that carbon nanotubes are able to cross the cellular membrane and accumulate in the cytoplasm-an area toxic to cells up to $10 \mathrm{mM}$ (Pantarotto et al., 2004). In another study, functionalized carbon nanotubes were designed with $B$ and $T$ cell peptide epitopes generating a multivalent system able to induce a strong immune response (Pantarotto et al., 2003). Carbon nanotubes open innumerable possibilities for the future of rational drug design and provide an innovative nanoarchitecture for drug development.

\section{Fullerenes.}

The science of functionalized fullerenes is rapidly expanding toward preclinical and clinical application. Fullerenes are spherical molecules that consist of 60 carbon atoms arranged in 12 pentagons and 20 hexagons (Ji et al., 2008). They exhibit extremely high hydrophobicity and photoactivity, strong cohesive force between inner molecules, and the ability to accept and release electrons that produce structural modifications. Studies on fullerenes suggested low toxicity (Nelson et al., 1993; Kolosnjaj et al., 2007) and current reports show their antioxidant activity (Enes et al., 2006). Depending on the functional group, fullerene substituents can modulate their water-soluble behavior, pharmacokinetic properties, serum protein binding, and sanguineous circulation-including transport via the blood-brain barrier and lipid membranes (Richardson et al., 2000; Bedrov et al., 2008; Nakamura \& Isobe, 2003). In addition, it has been demonstrated that fullerenes and their derivates have antiviral activity against influenza virus $\mathrm{H} 1 \mathrm{~N} 1$ (Ji et al.), cytomegalovirus (Medzhidova et al., 2004), and HIV (Marchesan et al., 2005; Bakry et al., 2007). Their favorable characteristics and physical properties make fullerenes an ideal drug candidate and will propel the research of fullerenes in multiple pharmacological arenas.

\section{Nanoshells, Nanorods and Gold Nanospheres.}

Based on the resonant absorption and light scattering properties of noble metal nanopaticles (i.e. Au or Ag), new strategies for medical therapy and diagnostics have recently been developed. These noble metals have been constructed with nanoarchitectures in the 100 $\mathrm{nm}$ diameter size range to form nanoshells and nanorods. Nanoshells are spherical nanoparticles that typically have a silica core and a metallic shell layer. When illuminated at wavelengths just beyond the visible spectrum in the near-infrared (NIR), they exhibit highly photothermal heating and scatter light modalities (Diagaradjane et al., 2008; Eghtedari et al., 2009). The funtionalization of the surface of these nanoparticles through the attachment of molecules, such as poly (ethylene glycol) (PEG), provides these nano-entities with an extended blood circulation time and enhanced passive accumulation into tumoral cells (Lowery et al., 2006). In addition, nanorods synthesized using noble metals are especially attractive for photothermal therapy because they can be built with different aspect ratios that allow selective absorption in the NIR region and can bind targeting nanomaterial-based drugs when their surface is coated with functional groups like aptamers and peptides (Huang et al., 2008; Oyelere et al., 2007).

The use of spherical gold nanoparticles, containing a $\mathrm{pH}$-sensititive surface and a relative size of $10 \mathrm{~nm}$, has recently been described as an innovative method for photothermal therapy. In a reduced $\mathrm{pH}$ environment, such as the endosomal area of neoplasic cells, these nanoparticles form intracellular aggregates that demonstrate a better photothermal response at longer NIR wavelengths. The principal advantages of photothermal treatment through nanoshells, nanorods, and gold nanospheres are their non-invasive modality, high biocompatibility, and low toxicity that enable their use in the development of new therapeutic agents (Ratto et al., 2009; Lal et al., 2008).

\section{Magnetic Nanoparticles.}

Magnetic nanoparticles (MNPs) offer a multifunctional toolbox for biomedical 
diagnostics and therapeutics as well as drug discovery and design with efficient structureactivity (Jun et al., 2008; Sakamoto et al., 2009). Strategies that involve the attachment of antibodies, ligands, or receptors to the surface of magnetic nanoparticles aim to manipulate the external magnetic fields to control specific cell functions (Dobson; Gao et al., 2009a, 2009b).

The induction of hyperthermia from magnetic nanoparticles was initially described more than fifty years ago as a plausible method for cancer treatment, but it has not yet reached standard clinical application because of difficulties attaining efficient tissue temperatures (Gilchrist et al., 1957). The study of magnetic nanoparticles in cancer research is propelled by the idea that when these particles are introduced to cancer cells and heated to $43^{\circ} \mathrm{C}$ by alternating external magnetic fields there is a sudden demise in cancer cell populations. This phenomenon shows promise because, while cancer cells perish at $43^{\circ} \mathrm{C}$, healthy tissues continue to thrive (Corchero \& Villaverde, 2009; Motoyama et al., 2008).
Because of the high magnetic moment of nanoparticles like those containing cobalt and nickel, there are limited uses for such nanoparticles in biomedical applications because of their increased toxicity level and susceptibility to oxidation. However, ferromagnetic nanoparticles like magnetite (Fe304) and maghemite ( $\mathrm{g}-\mathrm{Fe} 2 \mathrm{O} 3$ ) are highly biocompatible; the iron excess in the cell is controlled by uptake, excretion, and storage. Moreover, ferromagnetic nanoparticles can be efficiently cleared from the body and do not cause oxidative stress or longterm changes to liver enzyme levels (Corchero \& Villaverde; Jain et al., 2008). The potential of magnetic nanoparticles in the field of nanomedicine is substantial and will offer unique possibilities for new strategies to emerge in drug design.

\section{Drug Delivery.}

\section{Features of Drug Delivery Systems.}

Nanomedicine includes the development of nanodevices and nanoanalytical techniques

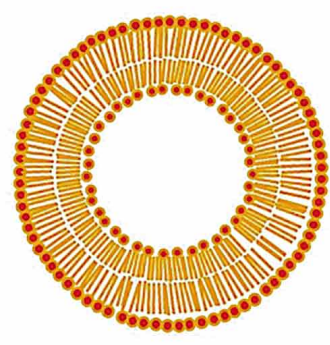

Liposome

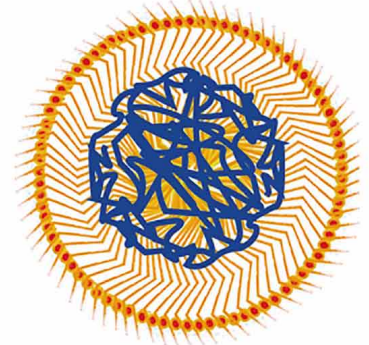

Polymeric

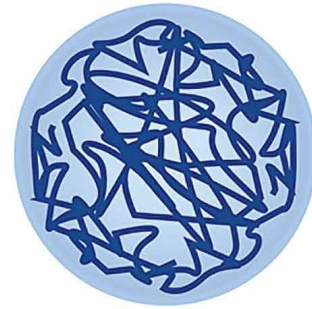

Polymeric Nanoparticle

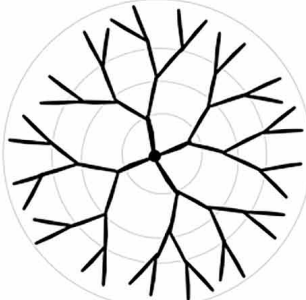

Dendrimer

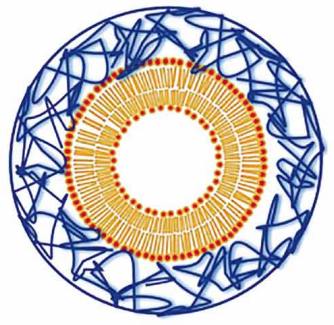

Polymeric-caged Liposome

Fig. 3. Schematic illustration of nanoparticle based-nanoproducts under preclinical and clinical development; as well as, marketed drug delivery systems. 
Table I. Some of clinically approved nanotechnology-based products available on the market.

\begin{tabular}{|c|c|c|}
\hline Product & Composition & Indication \\
\hline Adagen & PEGylated adenosine deaminase & Severe Combined \\
\hline Oncaspar & PEGylated L-asparaginase & Acute Iymphoblastic leukemia \\
\hline Doxil/Caelyx & PEGylated Liposomal doxorubicin & HIV-related Kaposi Sarcoma, \\
\hline Abelcet & Lipid Complex amphotericin B & Fungal Infections \\
\hline DaunoXome & Liposomal daunorubicin & Kaposi Sarcoma, HIV infections \\
\hline Copaxone & $\begin{array}{l}\text { L-glutamic acid, L-alanine, L- } \\
\text { tyrosine, and L-lysine copolymer }\end{array}$ & Multiple sclerosis \\
\hline AmBisome & Liposomal amphotericin B & Fungal Infections \\
\hline Ontak & IL2 fused to diphtheria toxin & Cutaneous t-cell lymphoma \\
\hline DepoCyt & Liposomal cytarabine & lymphomatous meningitis \\
\hline Rapamune & Nanocrystalline sirolimus & Immunosuppressant \\
\hline Visudyne & Liposomal verteporfin & Age-related macular degeneration \\
\hline Mylotarg & $\begin{array}{l}\text { Anti-CD33 antibody conjugated to } \\
\text { calicheamicin }\end{array}$ & Acute myelogenous leukemia \\
\hline Renagel & Poly(allylamine hydrochloride) & Chronic Kidney Disease \\
\hline Neulasta & PEGylated GCSF & Neutropenia \\
\hline Zevalin & $\begin{array}{l}\text { Anti-CD20 conjugated to yttrium- } \\
90 \text { or indium- } 111\end{array}$ & Non-Hodgkin's Iymphoma \\
\hline $\begin{array}{l}\text { Pegasys } \\
\text { Bexxar } \\
\text { Estrasorb }\end{array}$ & $\begin{array}{l}\text { PEGylated- } \alpha \text {-interferon } 2 a \\
\text { Anti-CD20 conjugated to iodine- } \\
\text { Micellular estradiol }\end{array}$ & $\begin{array}{l}\text { Hepatitis B, Hepatitis C } \\
\text { Non-Hodgkin's Iymphoma } \\
\text { Menopausal symptoms }\end{array}$ \\
\hline DepoDur & Liposomal morphine & Analgesia \\
\hline Tricor & Nanocrystalline fenofibrate & Lipid regulation \\
\hline Macugen & PEGylated anti-VEGF aptamer & Age-related macular degeneration \\
\hline Abraxane & Albumin-bound paclitaxel & Metastatic breast cancer \\
\hline Megace ES & Nanocrystalline megesterol acetate & Eating disorders, malnutrition, \\
\hline Emend & Nanocrystalline aprepitant & Chemotherapy induced nausea and \\
\hline $\begin{array}{l}\text { Invega- } \\
\text { Sustenna }\end{array}$ & $\begin{array}{l}\text { Nanocrystalline paliperidone } \\
\text { palmitate }\end{array}$ & Schizophrenia \\
\hline
\end{tabular}

for the molecular diagnostics, treatment, and prevention of disease (in terms of pain reduction and preserving or improving human health) (Freitas, 2005). Drug delivery is a key component in the development of nanomedicine (Lehr, 2009). In fact, there are more than thirty FDA-approved nanotechnology-based products currently in the market (Table I), and more than 130 nanotech-based drugs and delivery systems under development worldwide (No authors listed, 2006; Jain, 2009). New theraputic strategies include the targeted delivery of drugs that are cell-tissue specific, the use of therapies combined with agents that allow for the imaging of liberation sites (Lee et al., 2009), delivery systems that transcend the epithelial and endothelial barriers (Barbu et al., 2009), the intracellular delivery of macromolecules, improvements in poorly water-soluble drugs, the co-liberation of therapeutic agents, and the improvement of effective therapies (Farokhzad \& Langer, 2009). In several cases, the nanoarchitechture of nanocarriers is a perfect example of nanoengineering that combines cellular components and nanomaterials technology. Currently, there is a broad range of nanocarriers-such as liposomes, polymeric micelles, polymeric nanoparticles and dendrimers - that continually promise to revolutionize the future of medicine (Fig. 3).

\section{Passive and Active Targeting.}

Two general mechanisms of targeting have thus far been described: passive and active targeting. Passive targeting takes advantage of the enhanced permeation and retention (EPR) of the vascular and lymphatic drainage that occurs in the neoplasic process. It allows the nanocarrier to extravasate and accumulate within the tumor cell prior to delivery of the encapsulated drug (Greish et al., 2007; Oyewumi et al., 2004; Peer et al., 2007; Matsumura \& Maeda, 1986; Duncan et al., 
1999). When designing drug delivery platforms that utilize passive transport targeting, it is important to consider such physicochemical properties of the nanocarrier such as size, charge, and surface composition. These characteristics provide the nanoparticle with an optimal half-life and a better biodistribution (Farokhzad \& Langer; Gu et al., 2008). Active targeting involves the interactions between biologically active molecules, or cellular receptors expressed differentially in pathological cells and tissue, and functional groups bound to the surface of nanoparticles. The interaction between these biologically active molecules, cellular receptors, and functional groupsresults in the targeted delivery and controlled release of drugs. There are a broad range of targeting ligands with different specificity and chemical natures, including: monoclonal antibodies and their fragments (antigen-binding fragment Fab, dimers of antigen-binding fragment $F\left(a b^{\prime}\right) 2$, single chain fragment variable (ScFv) antibodies), peptides, aptamers, vitamines, and carbohydrates (Peer et al.). Another group of active targeting mechanisms that has the potential to play an important role in the future of drug delivery systems are aptamers. Aptamers are RNA or DNA oligonucleotides that are folded via intramolecular interactions into unique three-dimensional conformations and have highly favorable characteristics such as small size, lack of immunogenicity, ease of isolation, and the ability to bind with target antigens with high affinity and specificity. Aptamers have progressed into clinical trials and promise to be important in new cancer therapies (Farokhzad et al., 2006; Soundararajan et al., 2008).

\section{Nanoplatforms for Drug Delivery.}

\section{Liposomes.}

Liposome-based platforms are the most clinically established nanosystem for drug delivery (Gregoriadis, 1988). Liposomes are vesicles composed essentially of a phospholipid bilayer and have an internal and external aqueous phase (Newman et al., 1999). Liposomes are ideal candidates for drug delivery because of their ability to encapsulate hydrophobic drugs and interact with hydrophilic regions in their surrounding environment (Chen et al., 2007). Other important features of liposome-based platforms are biocompatibility, size flexibility, capacity for increased efficiency and reduced toxicity to the active encapsulated compound, prolonged therapeutic effectiveness, better absorption, penetration, and diffusion (Gabizon et al., 2006; Garg \& Jain, 2006). Liposomes were the first nanocarriers approved by the FDA for use in humans and their application has opened new frontiers in nanomedicine (Bawarski et al., 2008). Presently, there are numerous liposome-based nanoproducts in the market to treat pathologies like Kaposi sarcoma (DaunoXome) (Rosenthal et al., 2002), breast cancer (Myocet) (Mrozek et al., 2005; Poletti et al., 2008), age-related muscular degeneration (Visudyne) (No authors listed, 2000), and other types of cancer (Doxil, Caelyx, Depocyt) (Johnston \& Kaye, 2001; Porche, 1996; (No authors listed, 1995; Wagner et al., 2006; Craig, 2000).

\section{Polymeric Nanoparticles.}

The development of technologies comprised of biocompatible and biodegradable polymers have provided new therapeutic strategies in biomedicine Uhrich et al., 1999). Biodegradable and biocompatible synthetic polymers are the youngest members in the family of polymers (Kumar \& Kumar, 2001), and have been widely used in the pharmaceutical and biomedical engineering industries. Products have been systematically designed using polymer-based nanoparticles to promote the regeneration of ligaments, tissues, and cartilages (Kim et al., 2006). In addition, these polymers are essential to cellular proliferation (Newman \& McBurney, 2004), the development of anti-tumor therapies (Zhang \& Gao, 2007), and the fixation of surgical and medical devices (Hickey et al., 2002).

Polymer-based nanoparticles have been crucial to the development of drug delivery systems because of the ability to modify their physical and mechanical properties. Such polymeric alterations can control the pharmacokinetic properties of drug release and can change the biological activity of drugs (Gimeno et al., 2002; Tekade \& Gattani, 2009; Asane et al., 2008; O'Hagan etal., 2006), poly(Llactide) (Liu et al., 2009), poly(D,L lactide-co- 
glycolide) (Tsukada et al., 2009; Bertram et al., 2009; Miao et al., 2008; Xu et al., 2009), polysebacic anhydride (Furtado et al., 2008), and poly-e-caprolactone (Park et al., 2005; Wang et al., 2008; Belmayor et al., 2009) are some of the most commonly used polymers, which, when conjugated with molecules like polyethylenglycol (PEG), have a better blood circulation and clearance (Kaul \& Amiji, 2005). In addition, it has been found that the use of lipid-PEG-methoxy in functionalized nanoparticles is ideal for drug delivery applications because of the lack of aversive immunological reactions in the human body (Salvador-Morales et al., 2009).

Polymeric nanoparticles have been formulated to deliver a broad range of drugs including: glucocorticoid steroid (Ishihara et al., 2009), antirretroviral (Govender et al., 2008), nucleic acids (Patil \& Panyam, 2009), and chemotherapeutics (Parveen \& Sahoo, 2008).

\section{Polymeric Micelles.}

Polymeric micelles are spherical nanosized particles with a hydrophobic core and a hydrophilic shell that are formed from the selfassembly of biocompatible amphiphilic block copolymers in aqueous environments. They are considerably more stable than surfactant micelles and have been used as drug carriers for poorly water-soluble drugs (Jones \& Leroux, 1999).

The broad development of biodegradable polymers has made numerous materials ideal candidates for micelle synthesis. The formation of polymeric micelles enables the biphasic release of hydrophilic and hydrophobic drugs, and improves their behavior into sanguineous circulation (Gaucher et al., 2005). In fact, several anticancer formulations of poorly water-soluble drugs are currently undergoing preclinical and phase I/II clinical trials (Table II). Encapsulated by nanosized polymeric micelles, these drugs demonstrate superior anti-tumor efficacy, solubility, and reduced toxicity to humans (Tang et al., 2007; Shin et al., 2009). Recently, strategies have focused on developing lipidenveloped biodegradable polymer nanoparticles in order to combine the liposomal properties for blood circulation and stability given for the physico-chemical properties of polymers (Chan et al., 2009). Furthermore, surface modifications provide these polymer entities with increased longevity and stability during circulation, and improve their biodistribution and targeting effect (Torchilin, 2007).

\section{Dendrimers.}

Dendritic polymers, or dendrimers, present an alternative route to create welldefined nanostructures appropriate for drug delivery (Gillies \& Frechet; Cloninger, 2002; Lee et al., 2005; Guillaudeu et al., 2008). Dendrimers are nanostructures with a branched architecture, organized in a layered fashion, with each layer containing branching units two to three times the number of peripheral groups. According to the methods of synthesis, it is possible to precisely manipulate the molecular weight and chemical composition of dendrimers, thereby changing their capacity to bind to functional groups, as well as their pharmacokinetics and biocompatibility properties (Lee et al., 2005). In the preclinical stages of development, dendrimers are currently being studied to determine their effects on the silencing of genes (Patil et al., 2008, 2009; Pan et al., 2009), to develop doxorubicin-PAMAM for oral administration (Ke et al., 2008), and to form novel anti-tumor drugs (Choe et al., 2002; Zhuo et al., 1999).

\section{Polymer-caged liposomes.}

A new drug delivery nanosystem has recently been developed combining the excellent pharmacokinetics properties of liposomes and the high stability of polymers to form polymer-caged liposomes. Their nanoarchitecture has a liposome-based core and a cage-based-polymer conjugated with cholesterol-terminated poly(acrylic acid) (CholPAA) that induces drug release under acidic conditions (Lee et al., 2007). In addition, the cross-linking of functional groups and folic acid has provided a platform for the development of targeting strategies (Lee et al., 2009). Advancements in technology has made it possible to develop this hybrid formulation of polymers and liposomes and will lead the way to many future endeavors and breakthroughs in the realm of nanotechnology and medicine. 
VILOS, C. Nanotechnology in preclinical and clinical drug development. Int. J. Med. Surg. Sci., 1(1):73-93, 2014.

Table II. Nanoparticle-based products in clinical development.

\begin{tabular}{|c|c|c|c|c|}
\hline Product & Composition & Indication & Status & Source \\
\hline \multicolumn{5}{|c|}{ Lip osome based products } \\
\hline Alocrest & $\begin{array}{l}\text { Liposomal } \\
\text { Vinorelbine }\end{array}$ & $\begin{array}{l}\text { Solid tumors, Hodgkins } \\
\text { Diesase, Non-Hodgkins } \\
\text { Lymphoma }\end{array}$ & Phase I & Hana Biosciences \\
\hline BAY-7980 & Liposomal rFVIII & Hemophilia A & Phase I & Bayer \\
\hline LEP-ETU & Liposomal paclitaxel & Neoplasm, breast cancer & Phase I & NeoPharm \\
\hline $\begin{array}{l}\text { L-Annamycin } \\
\text { a) CP-105 } \\
\text { b) CP-103 }\end{array}$ & Liposomal anamycin & $\begin{array}{l}\text { a) Pediatric leukemia and } \\
\text { b) refractory or relapsed } \\
\text { acute lymphocytic } \\
\text { leukemia. }\end{array}$ & $\begin{array}{l}\text { a) Phase I } \\
\text { b) Phase } \\
\text { I/II }\end{array}$ & Calliso Pharmaceuticals \\
\hline LE-SN38 & Liposomal SN-38 & Colorectal cancer & Phase II & NeoPharm \\
\hline Marqibo & vincristine sulfate liposomes & $\begin{array}{l}\text { Acute Lymphoblastic } \\
\text { Leukemia, Melanoma }\end{array}$ & Phase II & Hana Biosciences \\
\hline Stimuvax & BLP25 liposome vaccine & $\begin{array}{l}\text { Non-small cell lung } \\
\text { cancer }\end{array}$ & Phase III & Oncothyreon \& Merck \\
\hline \multicolumn{5}{|c|}{ Polymer based products } \\
\hline CALAA-01 & $\begin{array}{l}\text { Cyclodextrin-based polymer- } \\
\text { siRNA }\end{array}$ & Solid tumor cancer & Phase I & Calando Pharmaceuticals \\
\hline$E Z N-2208$ & PEGylated SN-38 & $\begin{array}{l}\text { Colorectal cancer, } \\
\text { Iymphoma }\end{array}$ & Phase I/II & Enzon Pharmaceuticals \\
\hline Nanoplatin & Polymeric micelle-cisplatin & Various cancers & Phase I/II & NanoCarrier \\
\hline NK012 & Polymeric micelle-SN-38 & $\begin{array}{l}\text { Small-cell lung cancer, } \\
\text { breast cancer }\end{array}$ & Phase II & Nippon Kayaku \\
\hline NK105 & Polymeric micelle-paclitaxel & Various cancers & Phase II & $\begin{array}{l}\text { NanoCarrier \& Nippon } \\
\text { Kayaku }\end{array}$ \\
\hline NKTR-102 & PEGylated irinotecan & Various cancers & Phase II & Nektar \\
\hline NKTR-118 & PEG-naloxol & $\begin{array}{l}\text { Opioid-indu ced } \\
\text { constipation }\end{array}$ & Phase II & Nektar \\
\hline ProLindac & $\begin{array}{l}\text { HPMA copolymer-DACH } \\
\text { platinate }\end{array}$ & Ovarian Cancer & Phase II & Access Pharmaceuticals \\
\hline Opaxio & Paclitaxel poliglumex & Lung, ovarian cancer & Phase III & Cell Therapeutics \\
\hline Oxaliplatin & $\mathrm{DACH}$-platin Michelle & Colorectal cancer & Phase III & NanoCarrier \\
\hline PK1 & HPMA copolymer-doxorubicin & Breast Cancer & Phase III & Cancer Research UK \\
\hline \multicolumn{5}{|c|}{ Other products } \\
\hline Aurimune & $\begin{array}{l}\text { PEGylated colloidal gold-TNF } \\
\text { (colloidal gold nanoparticle) }\end{array}$ & Solid tumors & Phase I & CytImmune Sciences \\
\hline FT-105 & $\begin{array}{l}\text { Long-acting basal insulin } \\
\text { (poly-aminoacid nanoparticle) }\end{array}$ & Type II diabetes & Phase I & Flamel Technologies \\
\hline ABI-008 & $\begin{array}{l}\text { nab-docetaxel (albumin-shell } \\
\text { nanoparticle) }\end{array}$ & Prostate cancer & Phase I/II & Abraxis BioScience \\
\hline Rexin-G & $\begin{array}{l}\text { Cytocidal cyclin G1 } \\
\text { (pathotropic nanoparticle) }\end{array}$ & $\begin{array}{l}\text { Pancreas cancer, } \\
\text { osteosarcoma, and soft } \\
\text { tissue sarcoma }\end{array}$ & Phase I/II & Epius Biotechnologies \\
\hline IFN Alpha XL & $\begin{array}{l}\text { Long-acting interferon } \alpha-2 b \\
\text { (poly-aminoacid nanoparticle) }\end{array}$ & Hepatitis C & Phase II & Flamel Technologies \\
\hline Indaflex & $\begin{array}{l}\text { Nanoparticulate emulsion (oil- } \\
\text { in-water)-Indomethacin } \\
\text { (Nano-size oil droplets) }\end{array}$ & Analgesic & Phase II & AlphaRx \\
\hline NB-002 & $\begin{array}{l}\text { Nanoemulsion-based therapy } \\
\text { (nanoemulsion oil droplets) }\end{array}$ & Onychomycosis & Phase II & NanoBio \\
\hline Panzem NCD & $\begin{array}{l}\text { Nanocrystalline 2- } \\
\text { methoxyestradiol } \\
\text { (Nanocrystal) }\end{array}$ & Various Cancers & Phase II & EntreMed, Elan \\
\hline
\end{tabular}

\section{Challenges.}

\section{Concerns of Nanotechnology.}

The use of nanotechnology in the pharmaceutical industry (Ke et al.), medi- cine (Choe et $a /$. ), and engineering technology (Gu et al., 2009; Biesterfeld et al., 2001) has expanded rapidly over the last two decades. As a result, concerns for the environment and human health are increasing because each nanosystem has 
unique properties and their toxicities are not well defined (Lee et al., 2007). Moreover, organizations like the National Science and Technology Council (NSTC), National Research Council (NRC), National Nanotechnology Initiative (NNI), and the Nanotechnology Environmental and Health Implications (NEHI) have implemented strategies to regulate the use of different nano-based drug development and delivery systems that are outlined in the "Strategy for Nanotechnology-Related Environmental, Health, and Safety Research (EHS)" (Tsuji et al., 2006; Farokhzad et al., 1996).

Currently, there are in vitro methods to assess the risk of the various nano-based drug delivery platforms. However, a primary challenge in the near future is to develop standardized regulations that will assuage concerns for the environment and human health (Shelley et al., 1993; Feldkamp, 2009).

\section{Nanotechnology in Personalized Medicine.}

Personalized medicine refers to the specific prescription of the best treatment method available for an individual, considering the genetic and environmental factors that might influence his or her response to therapy (Jain, 2002). To achieve this goal, it is crucial to develop techniques with high specificity and diagnostic sensitivity, as well as effective therapeutic agents. In this context, nanobiotechnology has contributed significantly to the area of personalized medicine by offering innovative technologies that have refined methods for disease diagnosis and platforms for targeted drug release (Jain, 2004, 2009). The current use of nanoproducts in clinical practice is emerging and is an essential component in various medical procedures. As a result, nanotechnology is impacting the different phases of drug development and promises to be the key to achieve personalized medicine.

VILOS, C. La nanotecnología en el desarrollo preclínico y clínico de fármacos. Int. J. Med. Surg. Sci., 1(1):7393, 2014.

RESUMEN: La nanotecnología está generando un fuerte impacto en el desarrollo de fármacos preclínicos y clínicos. La diversidad de las nanotecnologías actuales ofrecen una amplia plataforma utilizada para mejorar el desempeño del descubrimiento de medicamentos, el desarrollo de métodos sensibles y específicos que se utilizan para dar a conocer los mecanismos detrás de las acciones de los fármacos, para determinar la función e interacción entre las moléculas y estudiar los efectos fisiológicos y cambios patológicos de los componentes celulares. Además, los avances en la nanobiotecnología han llevado al diseño de nuevos candidatos basados en nanomateriales de medicamentos que presentan un nuevo enfoque para el diagnóstico médico y la terapéutica. La nanoarquitectura biocompatible de los nanovehículos comercializados y utilizados para la entrega de drogas ha aumentado la solubilidad y eficacia de los fármacos clásicos, y ha proporcionado la tecnologíanecesaria para la acción selectiva de agentes terapéuticos encapsulados específicos para tejidos y órganos. Debido a su impacto en el desarrollo de medicamentos, la nanotecnología es la base para muchos esfuerzos médicos futuros. Este artículo proporciona una visión general de los conceptos básicos de la nanobiotecnología y discute sus aplicaciones en el descubrimiento de fármacos, su diseño y los sistemas de liberación.

PALABRAS CLAVE: Nanotecnología; Nanobiotecnología; Desarrollo de fármacos; Liberación de fármacos.

\section{REFERENCES}

Alexis, F.; Pridgen, E.; Molnar, L. K. \& Farokhzad, O. C. Factors affecting the clearance and biodistribution of polymeric nanoparticles. Mol. Pharm., 5:505-15, 2008.

Andersen, E. S.; Dong, M.; Nielsen, M. M.; Jahn, K.; Subramani, R.; Mamdouh, W. ; Golas, M. M.; Sander, B. ; Stark, H. ; Oliveira, C. L. ; Pedersen, J. S.; Birkedal,
V.; Besenbacher, F.; Gothelf, K. V. \& Kjems, J. Selfassembly of a nanoscale DNA box with a controllable lid. Nature, 459:73-6, 2009.

Asane, G. S.; Nirmal, S. A.; Rasal, K. B.; Naik, A. A.; Mahadik, M. S. \& Rao, Y. M. Polymers for mucoadhesive drug delivery system: a current status. Drug. Dev. Ind. Pharm., 34:1246-66, 2008. 
VILOS, C. Nanotechnology in preclinical and clinical drug development. Int. J. Med. Surg. Sci., 1(1):73-93, 2014.

Baca, H. K.; Carnes, E.; Singh, S.; Ashley, C.; Lopez, D. \& Brinker, C. J. Cell-directed assembly of bio/nano interfaces-a new scheme for cell immobilization. Acc. Chem. Res., 40:836-45, 2007.

Bakry, R.; Vallant, R. M.; Najam-ul-Haq, M.; Rainer, M.; Szabo, Z.; Huck, C. W. \& Bonn, G. K. Medicinal applications of fullerenes. Int. J. Nanomedicine, 2:639-49, 2007.

Balmayor, E. R.; Tuzlakoglu, K.; Azevedo, H. S. \& Reis, R. L. Preparation and characterization of starch-poly-epsiloncaprolactone microparticles incorporating bioactive agents for drug delivery and tissue engineering applications. Acta Biomater., 5:1035-45, 2009.

Barbu, E.; Molnar, E.; Tsibouklis, J. \& Gorecki, D. C. The potential for nanoparticle-based drug delivery to the brain: overcoming the blood-brain barrier. Expert Opin. Drug Deliv., 6:553-65, 2009.

Bawarski, W. E.; Chidlowsky, E.; Bharali, D. J. \& Mousa, S.A. Emerging nanopharmaceuticals. Nanomedicine, $4: 273-82,2008$.

Bedrov, D.; Smith, G. D.; Davande, H. \& Li, L. Passive transport of $\mathrm{C} 60$ fullerenes through a lipid membrane: a molecular dynamics simulation study. J. Phys. Chem. B, 112:2078-84, 2008.

Benoit, M. ; Gabriel, D. ; Gerisch, G. \& Gaub, H. E. Discrete interactions in cell adhesion measured by singlemolecule force spectroscopy. Nat. Cell Biol., 2:3137, 2000.

Bertram, J. P.; Jay, S. M.; Hynes, S. R.; Robinson, R.; Criscione, J. M. \& Lavik, E. B. Functionalized poly(lactic-co-glycolic acid) enhances drug delivery and provides chemical moieties for surface engineering while preserving biocompatibility. Acta Biomater., 5(8):2860-71, 2009.

Biesterfeld, S.; Farokhzad, F.; Kluppel, D.; Schneider, S. \& Hufnagl, P. Improvement of breast cancer prognostication using cell kinetic-based silverstainable nucleolar organizer region quantification of the MIB-1 positive tumor cell compartment. Virchows Arch., 438:478-84, 2001.

Bruce, P. G. ; Scrosati, B. \& Tarascon, J. M. Nanomaterials for rechargeable lithium batteries. Angew Chem. Int. Ed. Engl., 47:2930-46, 2008.

Chan, J. M.; Zhang, L.; Yuet, K. P.; Liao, G.; Rhee, J. W. ; Langer, R. \& Farokhzad, O. C. PLGA-lecithin-PEG core-shell nanoparticles for controlled drug delivery. Biomaterials, 30:1627-34, 2009.

Chen, L. Y. Monitoring conformational changes of immobilized RNase $A$ and lysozyme in reductive unfolding by surface plasmon resonance. Anal. Chim. Acta, 631:96-101, 2009.
Chen, H. \& Li, J. Nanotechnology: moving from microarrays toward nanoarrays. Methods Mol. Biol., 381:411-36, 2007.

Chen, H.; Gao, J.; Wang, F. \& Liang, W. Preparation, characterization and pharmacokinetics of liposomes-encapsulated cyclodextrins inclusion complexes for hydrophobic drugs. Drug Deliv., 14:201-8, 2007.

Chen, S.; Yu, Q. ; Li, L.; Boozer, C. L. ; Homola, J.; Yee, S. S. \& Jiang, S. Detecting the adsorption of dye molecules in homogeneous poly(propylene imine) dendrimer monolayers by surface plasmon resonance sensor. J. Am. Chem. Soc., 124:3395$401,2002$.

Chien, F. T. \& van Noort, J. 10 years of tension on chromatin: results from single molecule force spectroscopy. Curr. Pharm. Biotechnol., 10:47485, 2009.

Choe, Y. H.; Conover, C. D.; Wu, D.; Royzen, M.; Gervacio, Y.; Borowski, V.; Mehlig, M. \& Greenwald, R. B. Anticancer drug delivery systems: multiloaded N4-acyl poly(ethylene glycol) prodrugs of ara-C. II. Efficacy in ascites and solid tumors. J. Control Release, 79:55-70, 2002.

Cloninger, M. J. Biological applications of dendrimers. Curr. Opin. Chem. Biol., 6:742-8, 2002.

Corchero, J. L. \& Villaverde, A. Biomedical applications of distally controlled magnetic nanoparticles. Trends Biotechnol., 27:468-76, 2009.

Cormode, D. P.; Skajaa, T.; Fayad, Z. A. \& Mulder, W. J. Nanotechnology in medical imaging: probe design and applications. Arterioscler. Thromb. Vasc. Biol., 29:992-1000, 2009.

Craig, C. Current treatment approaches for neoplastic meningitis: nursing management of patients receiving intrathecal DepoCyt. Oncol. Nurs. Forum, 27:1225-30; quiz 1231-2, 2000.

Creutz, C. E. \& Edwardson, J. M. Organization and synergistic binding of copine I and annexin A1 on supported lipid bilayers observed by atomic force microscopy. Biochim. Biophys. Acta, 1788(9):1950$61,2009$.

Cruz Enriquez, A. ; Rivero Espejel, I. A. ; Andres Garcia, E. \& Diaz-Garcia, M. E. Enhanced resonance light scattering properties of gold nanoparticles due to cooperative binding. Anal. Bioanal. Chem., 391:807-15, 2008.

Cui, Y.; Wei, Q.; Park, H. \& Lieber, C. M. Nanowire nanosensors for highly sensitive and selective detection of biological and chemical species. Science, 293:1289-92, 2001. 
Daniels, A. U.; Chang, M. K. \& Andriano, K. P. Mechanical properties of biodegradable polymers and composites proposed for internal fixation of bone. J. Appl. Biomater., 1:57-78, 1990.

De Leebeeck, A. \& Sinton, D. Ionic dispersion in nanofluidics. Electrophoresis, 27:4999-5008, 2006.

Diagaradjane, P.; Shetty, A.; Wang, J. C. ; Elliott, A. M. ; Schwartz, J.; Shentu, S.; Park, H. C.; Deorukhkar, A.; Stafford, R. J.; Cho, S. H.; Tunnell, J. W.; Hazle, J. D. \& Krishnan, S. Modulation of in vivo tumor radiation response via gold nanoshell-mediated vascular-focused hyperthermia: characterizing an integrated antihypoxic and localized vascular disrupting targeting strategy. Nano Lett., 8:1492500, 2008.

Dimasi, J. A. New drug development in the United States from 1963 to 1999. Clin. Pharmacol. Ther., 69:286$96,2001$.

DiMasi, J. A.; Hansen, R. W. \& Grabowski, H. G. The price of innovation: new estimates of drug development costs. J. Health Econ., 22:151-85, 2003.

Djordjevic, A.; Bogdanovic, G. \& Dobric, S. Fullerenes in biomedicine. J. BUON, 11:391-404, 2006.

Dobson, J. Remote control of cellular behaviour with magnetic nanoparticles. Nat. Nanotechnol., 3:13943, 2008.

DOXIL approved by FDA. AIDS Patient Care, 9:306, 1995.

Duncan, R. Polymer conjugates for tumour targeting and intracytoplasmic delivery. The EPR effect as a common gateway? Pharm. Sci. Technol. Today, 2:441-9, 1999.

Edwardson, J. M. \& Henderson, R. M. Atomic force microscopy and drug discovery. Drug Discov. Today, 9:64-71, 2004.

Eghtedari, M.; Liopo, A. V.; Copland, J. A.; Oraevsky, A. A. \& Motamedi, M. Engineering of hetero-functional gold nanorods for the in vivo molecular targeting of breast cancer cells. Nano Lett., 9:287-91, 2009.

Eijkel, J. Nanofluidics. Anal. Bioanal. Chem., 394:3834, 2009.

Elie-Caille, C.; Severin, F.; Helenius, J.; Howard, J.; Muller, D. J. \& Hyman, A. A. Straight GDP-tubulin protofilaments form in the presence of taxol. Curr. Biol., 17:1765-70, 2007.

Enes, R. F.; Tomé, A. C.; Cavaleiro, J. A.; Amorati, R.; Fumo, M. G.; Pedulli, G. F. \& Valgimigli, L. Synthesis and antioxidant activity of [60]fullerene-BHT conjugates. Chemistry, 12:4646-53, 2006.
Farokhzad, O. C. Nanotechnology for drug delivery: the perfect partnership. Expert Opin. Drug Deliv., 5:92729, 2008.

Farokhzad, O. C. \& Langer, R. Impact of nanotechnology on drug delivery. ACS Nano, 3:16-20, 2009.

Farokhzad, O. C.; Karp, J. M. \& Langer, R. Nanoparticleaptamer bioconjugates for cancer targeting. Expert Opin. Drug Deliv., 3:311-24, 2006.

Farokhzad, O. C.; Shelley, C. S. \& Arnaout, M. A. Induction of the CD11b gene during activation of the monocytic cell line $U 937$ requires a novel nuclear factor MS-2. J. Immunol., 157:5597-605, 1996.

Feldkamp, U. CANADA: Designing nucleic acid sequences for nanobiotechnology applications. J. Comput. Chem., 31(3):660-3, 2010.

Freitas, R. A. Jr. What is nanomedicine? Dis. Mon., 51:325-41, 2005.

Furtado, S.; Abramson, D.; Burrill, R.; Olivier, G.; Gourd, C.; Bubbers, E. \& Mathiowitz, E. Oral delivery of insulin loaded poly(fumaric-co-sebacic) anhydride microspheres. Int. J. Pharm., 347:149-55, 2008.

Gabizon, A. A.; Tzemach, D.; Horowitz, A. T.; Shmeeda, H.; Yeh, J. \& Zalipsky, S. Reduced toxicity and superior therapeutic activity of a mitomycin $C$ lipid-based prodrug incorporated in pegylated liposomes. Clin. Cancer Res., 12:1913-20, 2006.

Gao, J.; Gu, H. \& Xu, B. Multifunctional Magnetic Nanoparticles: Design, Synthesis, and Biomedical Applications. Acc. Chem. Res., 42(8):1097-107, 2009.

Gau, V. \& Wong, D. Oral fluid nanosensor test (OFNASET) with advanced electrochemical-based molecular analysis platform. Ann. N. Y. Acad. Sci., 1098:401$10,2007$.

Garcia-Manyes, S.; Bucior, I.; Ros, R.; Anselmetti, D. ; Sanz, F.; Burger, M. M. \& Fernàndez-Busquets, X. Proteoglycan mechanics studied by single-molecule force spectroscopy of allotypic cell adhesion glycans. J. Biol. Chem., 281:5992-9, 2006.

Garg, M. \& Jain, N. K. Reduced hematopoietic toxicity, enhanced cellular uptake and altered pharmacokinetics of azidothymidine loaded galactosylated liposomes. J. Drug Target, 14:1-11, 2006.

Gaucher, G.; Dufresne, M. H.; Sant, V. P.; Kang, N.; Maysinger, D. \& Leroux, J. C. Block copolymer micelles: preparation, characterization and application in drug delivery. J. Control Release, 109:169-88, 2005. 
Gilbert, Y.; Deghorain, M.; Wang, L.; Xu, B.; Pollheimer, P. D.; Gruber, H. J.; Errington, J.; Hallet, B.; Haulot, X.; Verbelen, C.; Hols, P. \& Dufrêne, Y. F. Singlemolecule force spectroscopy and imaging of the vancomycin/D-Ala-D-Ala interaction. Nano Lett., 7:796-801, 2007.

Gilchrist, R. K.; Medal, R.; Shorey, W. D.; Hanselman, R. C.; Parrott J. C. \& Taylor, C. B. Selective inductive heating of lymph nodes. Ann. Surg., 146:596-606, 1957.

Gillies, E. R. \& Frechet, J. M. Dendrimers and dendritic polymers in drug delivery. Drug Discov. Today, 10:35-43, 2005.

Gimeno, M. J.; García-Esteo, F.; García-Honduvilla, N. ; Bellón, J. M.; Buján, J. \& Román, J. S. Polymer controlled drug delivery system for growth hormone. Drug Deliv., 9:233-7, 2002.

Goldberger, J.; Fan, R. \& Yang, P. Inorganic nanotubes: a novel platform for nanofluidics. Acc. Chem. Res., 39:239-48, 2006.

Govender, T.; Ojewole, E.; Naidoo, P. \& Mackraj, I. Polymeric nanoparticles for enhancing antiretroviral drug therapy. Drug Deliv., 15:493-501, 2008.

Guillaudeu, S. J.; Fox, M. E.; Haidar, Y. M.; Dy, E. E.; Szoka, F. C. \& Fréchet, J. M. PEGylated dendrimers with core functionality for biological applications. Bioconjug. Chem., 19:461-9, 2008.

Greish, K. Enhanced permeability and retention of macromolecular drugs in solid tumors: a royal gate for targeted anticancer nanomedicines. J. Drug Target, 15:457-64, 2007.

Gregoriadis, G. Liposomes as a drug delivery system: optimization studies. Adv. Exp. Med. Biol., 238:1519, 1988.

Gu, F.; Langer, R. \& Farokhzad, O. C. Formulation/ Preparation of functionalized nanoparticles for in vivo targeted drug delivery. Methods Mol. Biol., 544:58998, 2009.

Gu, F.; Zhang, L.; Teply, B. A.; Mann, N.; Wang, A.; Radovic-Moreno, A. F.; Langer, R. \& Farokhzad, O. C. Precise engineering of targeted nanoparticles by using self-assembled biointegrated block copolymers. Proc. Natl. Acad. Sci. U S A, 105:2586-91, 2008.

Haes, A. J.; Chang, L.; Klein, W. L. \& Van Duyne, R. P. Detection of a biomarker for Alzheimer's disease from synthetic and clinical samples using a nanoscale optical biosensor. J. Am. Chem. Soc., 127:2264-71, 2005.

Haes, A. J. \& Van Duyne, R. P. A nanoscale optical biosensor: sensitivity and selectivity of an approach based on the localized surface plasmon resonance spectroscopy of triangular silver nanoparticles. J. Am. Chem. Soc., 124:10596-604, 2002.

Hickey, T.; Kreutzer, D.; Burgess, D. J. \& Moussy, F. Dexamethasone/PLGA microspheres for continuous delivery of an anti-inflammatory drug for implantable medical devices. Biomaterials, 23:1649-56, 2002.

Hinterdorfer, P. \& Dufrene, Y. F. Detection and localization of single molecular recognition events using atomic force microscopy. Nat. Methods, 3:347-55, 2006.

Hong, J.; Edel, J. B. \& deMello, A. J. Micro- and nanofluidic systems for high-throughput biological screening. Drug Discov. Today, 14:134-46, 2009.

Huang, Y. F.; Sefah, K.; Bamrungsap, S. ; Chang, H. T. \& Tan, W. Selective photothermal therapy for mixed cancer cells using aptamer-conjugated nanorods. Langmuir, 24:11860-5, 2008.

Hughes, B. 2008 FDA drug approvals. Nat. Rev. Drug Discov., 8:93-6, 2009.

Hughes, S.; McBain, S.; Dobson, J. \& El Haj, A. J. Selective activation of mechanosensitive ion channels using magnetic particles. J. R. Soc. Interface, 5:855$63,2008$.

Initiative, N. N. Research and development leading to a revolution in technology and industry Supplement to the President's 2010 Budget, 2009.

Ishihara, T.; Kubota, T.; Choi, T. \& Higaki, M. Treatment of experimental arthritis with stealth-type polymeric nanoparticles encapsulating betamethasone phosphate. J. Pharmacol. Exp. Ther., 329:412-17, 2009.

Jain, K. K. The role of nanobiotechnology in drug discovery. Drug Discov. Today, 10:1435-42, 2005.

Jain, K. K. Nanomedicine: application of nanobiotechnology in medical practice. Med. Princ. Pract., 17:89-101, 2008.

Jain, T. K.; Reddy, M. K.; Morales, M. A.; Leslie-Pelecky, D. L. \& Labhasetwar, V. Biodistribution, clearance, and biocompatibility of iron oxide magnetic nanoparticles in rats. Mol. Pharm., 5:316-27, 2008.

Jain, K. K. Role of nanobiotechnology in the development of personalized medicine. Nanomed., 4:249-52, 2009.

Jain, K. K. Personalized medicine. Curr. Opin. Mol. Ther., 4:548-58, 2002.

Jain, K. K. Applications of biochips: from diagnostics to personalized medicine. Curr. Opin. Drug Discov. Devel., 7:285-9, 2004. 
Ji, H.; Yang Z, Jiang W, Geng C, Gong M, Xiao H, Wang $Z$, Cheng L. Antiviral activity of nano carbon fullerene lipidosome against influenza virus in vitro. $J$ Huazhong Univ Sci Technolog Med Sci 28: 243-246 (2008).

Jin, A. J.; Prasad, K.; Smith, P. D.; Lafer, E. M. \& Nossal, R. Measuring the elasticity of clathrin-coated vesicles via atomic force microscopy. Biophys. J., 90:333344, 2006.

Jones, M. \& Leroux, J. Polymeric micelles - a new generation of colloidal drug carriers. Eur. J. Pharm. Biopharm., 48:101-11, 1999.

Jun, Y. W.; Lee, J. H. \& Cheon, J. Chemical design of nanoparticle probes for high-performance magnetic resonance imaging. Angew Chem. Int. Ed. Engl., 47:5122-35, 2008.

Jung, M.; Oh, B. K. \& Choi, J. W. Fabrication of Au nanodots with $60 \mathrm{~nm}$ diameter on ITO glass: Towards nanobiochip using nanoporous alumina mask. Ultramicroscopy, 109:1006-10, 2009.

Johnston, S. R. \& Kaye, S. Caelyx: treatment for relapsing ovarian cancer. Hosp. Med., 62:611-6, 2001.

Kanno, T.; Yamada, T.; Iwabuki, H.; Tanaka, H. ; Kuroda, S.; Tanizawa, K. \& Kawai, T. Size distribution measurement of vesicles by atomic force microscopy. Anal. Biochem., 309:196-9, 2002.

Karlsson, A.; Karlsson, M.; Karlsson, R.; Sott, K.; Lundqvist, A.; Tokarz, M. \& Orwar, O. Nanofluidic networks based on surfactant membrane technology. Anal. Chem., 75:2529-37, 2003.

Kaul, G. \& Amiji, M. Tumor-targeted gene delivery using poly(ethylene glycol)-modified gelatin nanoparticles: in vitro and in vivo studies. Pharm. Res., 22:951-61, 2005.

Ke, W.; Zhao, Y.; Huang, R. ; Jiang, C. \& Pei, Y. Enhanced oral bioavailability of doxorubicin in a dendrimer drug delivery system. J. Pharm. Sci., 97:2208-16, 2008.

Kersey, F. R.; Yount, W. C. \& Craig, S. L. Single-molecule force spectroscopy of bimolecular reactions: system homology in the mechanical activation of ligand substitution reactions. J. Am. Chem. Soc., 128:3886-7, 2006.

Kim, S. S.; Sun Park, M.; Jeon, O.; Yong Choi, C. \& Kim, B. S. Poly(lactide-co-glycolide)/hydroxyapatite composite scaffolds for bone tissue engineering. Biomaterials, 27:1399-409, 2006.

Kneipp, J., Kneipp, H., Wittig, B. \& Kneipp, K. Novel optical nanosensors for probing and imaging live cells. Nanomedicine, 6(2):214-26, 2009.
Kolosnjaj, J.; Szwarc, H. \& Moussa, F. Toxicity studies of fullerenes and derivatives. Adv. Exp. Med. Biol., 620:168-80, 2007.

Kruithof, M.; Chien, F. T.; Routh, A.; Logie, C.; Rhodes, D. \& van Noort, J. Single-molecule force spectroscopy reveals a highly compliant helical folding for the 30$\mathrm{nm}$ chromatin fiber. Nat. Struct. Mol. Biol., 16:53440, 2009.

Kumar, N.; Parajuli, O. \& Hahm, J. I. Two-dimensionally self-arranged protein nanoarrays on diblock copolymer templates. J. Phys. Chem. B, 111:4581-7, 2007.

Kumar, M. N. \& Kumar, N. Polymeric controlled drugdelivery systems: perspective issues and opportunities. Drug Dev. Ind. Pharm., 27:1-30, 2001.

Lal, S.; Clare, S. E. \& Halas, N. J. Nanoshell-enabled photothermal cancer therapy: impending clinical impact. Acc. Chem. Res., 41:1842-51, 2008.

Law, M.; Kind, H.; Messer, B.; Kim, F. \& Yang, P. Photochemical sensing of $\mathrm{NO}(2)$ with $\mathrm{SnO}(2)$ nanoribbon nanosensors at room temperature. Angew Chem. Int. Ed. Engl., 41:2405-8, 2002.

Lee, S.; Lee, S.; Ko, Y. H.; Jung, H.; Kim, J. D.; Song, J. M.; Choo, J.; Eo, S. K. \& Kang, S. H. Quantitative analysis of human serum leptin using a nanoarray protein chip based on single-molecule sandwich immunoassay. Talanta, 78:608-12, 2009.

Lee, J. H.; Lee, K.; Moon, S. H.; Lee, Y.; Park, T. G. \& Cheon, J. All-in-one target-cell-specific magnetic nanoparticles for simultaneous molecular imaging and siRNA delivery. Angew Chem. Int. Ed. Engl., 48:41749, 2009.

Lee, S. M.; Chen, H.; Dettmer, C. M.; O'Halloran, T. V. \& Nguyen, S. T. Polymer-caged lipsomes: a $\mathrm{pH}$ responsive delivery system with high stability. J. Am. Chem. Soc., 129:15096-7, 2007.

Lee, S. M.; Chen, H.; O'Halloran, T. V. \& Nguyen, S. T. "Clickable" polymer-caged nanobins as a modular drug delivery platform. J. Am. Chem. Soc., 131:9311-20, 2009.

Lehr, C. M. Biological barriers and nanomedicine--timely challenges in advanced drug delivery research. Eur. J. Pharm. Biopharm., 72:287-8, 2009.

Lee, C. C.; MacKay, J. A.; Frechet, J. M. \& Szoka, F. C. Designing dendrimers for biological applications. Nat. Biotechnol., 23:1517-26, 2005.

Leonenko, Z. V.; Carnini, A. \& Cramb, D. T. Supported planar bilayer formation by vesicle fusion: the interaction of phospholipid vesicles with surfaces and the effect of gramicidin on bilayer properties using atomic force microscopy. Biochim. Biophys. Acta, 1509:131-47, 2000. 
VILOS, C. Nanotechnology in preclinical and clinical drug development. Int. J. Med. Surg. Sci., 1(1):73-93, 2014.

Liong, M.; Lu, J.; Kovochich, M.; Xia, T.; Ruehm, S. G.; Nel, A. E.; Tamanoi, F. \& Zink, J. I. Multifunctional inorganic nanoparticles for imaging, targeting, and drug delivery. ACS Nano, 2:889-96, 2008.

Liu, Q.; Cai, C. \& Dong, C. M. Poly(L-lactide)-bpoly(ethylene oxide) copolymers with different arms: hydrophilicity, biodegradable nanoparticles, in vitro degradation, and drug-release behavior. $J$. Biomed. Mater. Res. A, 88:990-9, 2009.

Lowery, A. R.; Gobin, A. M.; Day, E. S.; Halas, N. J. \& West, J. L. Immunonanoshells for targeted photothermal ablation of tumor cells. Int. J. Nanomedicine, 1:149-54, 2006.

Marchesan, S.; Da Ros, T.; Spalluto, G.; Balzarini, J. \& Prato, M. Anti-HIV properties of cationic fullerene derivatives. Bioorg. Med. Chem. Lett., 15:3615-8, 2005.

Maheshwari, G. ; Brown, G. ; Lauffenburger, D. A. ; Wells, A. \& Griffith, L. G. Cell adhesion and motility depend on nanoscale RGD clustering. J. Cell Sci, 113(Pt. 10): $1677-86,2000$.

Mannion, J. T. \& Craighead, H. G. Nanofluidic structures for single biomolecule fluorescent detection. Biopolymers, 85:131-43, 2007.

Mannix, R. J.; Kumar, S.; Cassiola, F.; Montoya-Zavala, M.; Feinstein, E.; Prentiss, M. \& Ingber, D. E. Nanomagnetic actuation of receptor-mediated signal transduction. Nat. Nanotechnol., 3:36-40, 2008.

Mao, S. \& Chen, X. Selected nanotechnologies for renewable energy applications. Int. J. Energy Res., 31:619-36, 2007.

Martin, C. R. \& Kohli, P. The emerging field of nanotube biotechnology. Nat. Rev. Drug Discov., 2:29-37, 2003.

Matsumura, Y. \& Maeda, H. A new concept for macromolecular therapeutics in cancer chemotherapy: mechanism of tumoritropic accumulation of proteins and the antitumor agent smancs. Cancer Res., 46:6387-92, 1986.

Medzhidova, M. G.; Abdullaeva, M. V.; Fedorova, N. E.; Romanova, V. S. \& Kushch, A. A. In vitro antiviral activity of fullerene amino acid derivatives in cytomegalovirus infection. Antibiot. Khimioter., 49:13-20, 2004.

Miao, L. F. ; Yang, J.; Huang, C. L.; Song, C. X.; Zeng, Y. J.; Chen, L. F. \& Zhu, W. L. Rapamycin-loaded poly (lactic-co-glycolic) acid nanoparticles for intraarterial local drug delivery: preparation, characterization, and in vitro/in vivo release. Zhongguo Yi Xue Ke Xue Yuan Xue Bao, 30:491-7, 2008.
Min, Y.; Akbulut, M.; Kristiansen, K.; Golan, Y. \& Israelachvili, J. The role of interparticle and external forces in nanoparticle assembly. Nat. Mater., 7:527$38,2008$.

Mingeot-Leclercq, M. P.; Deleu, M., Brasseur, R. \& Dufrene, Y. F. Atomic force microscopy of supported lipid bilayers. Nat. Protoc., 3:1654-9, 2008.

Mitchell, G.; Lamontagne, C. A.; Lebel, R.; Grandbois, M. \& Malouin, F. Single-molecule dynamic force spectroscopy of the fibronectin-heparin interaction. Biochem. Biophys. Res. Commun., 364:595-600, 2007.

Morris, M. \& Watkins, S. M. Focused metabolomic profiling in the drug development process: advances from lipid profiling. Curr. Opin. Chem. Biol., 9:40712, 2005.

Motoyama, J.; Hakata, T.; Kato, R.; Yamashita, N.; Morino, T.; Kobayashi, T. \& Honda, H. Size dependent heat generation of magnetite nanoparticles under AC magnetic field for cancer therapy. Biomagn. Res. Technol., 6:4, 2008.

Mrozek, E.; Rhoades, C. A.; Allen, J.; Hade, E. M. \& Shapiro, C. L. Phase I trial of liposomal encapsulated doxorubicin (Myocet; D-99) and weekly docetaxel in advanced breast cancer patients. Ann. Oncol., 16:1087-93, 2005.

Muller, D. J. Out and in: simplifying membrane protein studies by AFM. Biophys. J., 91:3133-4, 2006.

Muller, D. J. \& Dufrene, Y. F. Atomic force microscopy as a multifunctional molecular toolbox in nanobiotechnology. Nat. Nanotechnol., 3:261-9, 2008.

Nakamura, E. \& Isobe, H. Functionalized fullerenes in water. The first 10 years of their chemistry, biology, and nanoscience. Acc. Chem. Res., 36:807-15, 2003.

Nel, A. E.; Mädler, L.; Velegol, D.; Xia, T.; Hoek, E. M.; Somasundaran, P.; Klaessig, F.; Castranova, V. \& Thompson, M. Understanding biophysicochemical interactions at the nano-bio interface. Nat. Mater., 8:543-57, 2009.

Nelson, M. A.; Domann, F. E.; Bowden, G. T.; Hooser, S. B.; Fernando, Q. \& Carter, D. E. Effects of acute and subchronic exposure of topically applied fullerene extracts on the mouse skin. Toxicol. Ind. Health, 9:623-30, 1993.

Newman, M. S.; Colbern, G. T.; Working, P. K.; Engbers, C. \& Amantea, M. A. Comparative pharmacokinetics, tissue distribution, and therapeutic effectiveness of cisplatin encapsulated in long-circulating, pegylated liposomes (SPI-077) in tumor-bearing mice. Cancer Chemother. Pharmacol., 43:1-7, 1999. 
Newman, K. D. \& McBurney, M. W. Poly(D,L lactic-coglycolic acid) microspheres as biodegradable microcarriers for pluripotent stem cells. Biomaterials, 25:5763-71, 2004.

No authors listed. Photodynamic therapy with verteporfin (Visudyne) for macular degeneration. Med. Lett. Drugs Ther., 42:81-2, 2000.

No authors listed. Nanomedicine: a matter of rhetoric? Nat. Mater., 5:243, 2006.

Obare, S. O. \& Meyer, G. J. Nanostructured materials for environmental remediation of organic contaminants in water. J. Environ. Sci. Health $A$ Tox. Hazard Subst. Environ. Eng., 39:2549-82, 2004.

O'Hagan, D. T.; Singh, M. \& Ulmer, J. B. Microparticlebased technologies for vaccines. Methods, 40:109, 2006.

Oreopoulos, J. \& Yip, C. M. Combinatorial microscopy for the study of protein-membrane interactions in supported lipid bilayers: Order parameter measurements by combined polarized TIRFM/AFM. J. Struct. Biol., 168(1):21-36, 2009.

Oyelere, A. K.; Chen, P. C.; Huang, X.; El-Sayed, I. H. \& El-Sayed, M. A. Peptide-conjugated gold nanorods for nuclear targeting. Bioconjug. Chem., 18:14907, 2007.

Oyewumi, M. O.; Yokel, R. A.; Jay, M.; Coakley, T. \& Mumper, R. J. Comparison of cell uptake, biodistribution and tumor retention of folate-coated and PEG-coated gadolinium nanoparticles in tumorbearing mice. J. Control Release, 95:613-26, 2004.

Pan, B.; Cui, D.; Xu, P.; Ozkan, C.; Feng, G.; Ozkan, M.; Huang, T.; Chu, B.; Li, Q.; He, R. \& Hu, G. Synthesis and characterization of polyamidoamine dendrimer-coated multi-walled carbon nanotubes and their application in gene delivery systems. Nanotechnology, 20:125101, 2009.

Pantarotto, D.; Briand, J. P.; Prato, M. \& Bianco, A. Translocation of bioactive peptides across cell membranes by carbon nanotubes. Chem. Commun. (Camb.), (1):16-7, 2004.

Pantarotto, D.; Partidos, C. D. ; Graff, R.; Hoebeke, J.; Briand, J. P.; Prato, M. \& Bianco, A. Synthesis, structural characterization, and immunological properties of carbon nanotubes functionalized with peptides. J. Am. Chem. Soc., 125:6160-4, 2003.

Park, E. K.; Kim, S. Y.; Lee, S. B. \& Lee, Y. M. Folateconjugated methoxy poly(ethylene glycol)/ poly(epsilon-caprolactone) amphiphilic block copolymeric micelles for tumor-targeted drug delivery. J. Control Release, 109:158-68, 2005.
Parveen, S. \& Sahoo, S. K. Polymeric nanoparticles for cancer therapy. J. Drug. Target, 16:108-23, 2008.

Patil, Y. \& Panyam, J. Polymeric nanoparticles for siRNA delivery and gene silencing. Int. J. Pharm., 367:195203, 2009.

Patil, M. L. ; Zhang, M.; Taratula, O.; Garbuzenko, O. B. ; $\mathrm{He}, \mathrm{H}$. \& Minko, T. Internally cationic polyamidoamine PAMAM-OH dendrimers for siRNA delivery: effect of the degree of quaternization and cancer targeting. Biomacromolecules, 10:258-66, 2009.

Patil, M. L. ; Zhang, M.; Betigeri, S. ; Taratula, O.; He, H. \& Minko, T. Surface-modified and internally cationic polyamidoamine dendrimers for efficient siRNA delivery. Bioconjug. Chem., 19:1396-403, 2008.

Peer, D.; Karp, J. M.; Hong, S.; Farokhzad, O. C.; Margalit, R. \& Langer, R. Nanocarriers as an emerging platform for cancer therapy. Nat. Nanotechnol., 2:751-60, 2007.

Pillai, O. \& Panchagnula, R. Polymers in drug delivery. Curr. Opin. Chem. Biol., 5:447-51, 2001.

Poletti, P.; Bettini, A. C.; Caremoli, E. R. ; Labianca, R. \& Tondini, C. Liposomal-encapsulated doxorubicin (Myocet; D-99) and vinorelbine in previously treated metastatic breast cancer patients: a feasibility study. Tumori, 94:686-90, 2008.

Porche, D. J. Liposomal doxorubicin (Doxil). J. Assoc. Nurses AIDS Care, 7:55-9, 1996.

Powell, T.; Tran, P.; Kim, K. \& Yoon, J. J. Size-dependent self-assembly of submicron/nano beads-protein conjugates for construction of a protein nanoarray. Mater. Sci. Eng. C Mater. Biol. Appl., 29(8):24592463, 2009.

Prato, M.; Kostarelos, K. \& Bianco, A. Functionalized carbon nanotubes in drug design and discovery. Acc. Chem. Res., 41:60-8, 2008.

Ramakrishnan, M.; Kandimalla, K. K.; Wengenack, T. M.; Howell, K. G. \& Poduslo, J. F. Surface Plasmon Resonance Binding Kinetics of Alzheimer's Disease Amyloid Peptide Capturing- and Plaque BindingMonoclonal Antibodies. Biochemistry, 48(43):1040515,2009

Ratto, F.; Matteini, P.; Rossi, F.; Menabuoni, L.; Tiwari, N.; Kulkarni, S. K. \& Pini, R. Photothermal effects in connective tissues mediated by laser-activated gold nanorods. Nanomedicine, 5:143-51, 2009.

Richardson, C. F.; Schuster, D. I. \& Wilson, S. R. Synthesis and characterization of water-soluble amino fullerene derivatives. Org. Lett., 2:1011-4, 2000.

Riehemann, K.; Schneider, S. W.; Luger, T. A.; Godin, 
B.; Ferrari, M. \& Fuchs, H. Nanomedicine--challenge and perspectives. Angew Chem. Int. Ed. Engl., 48:872-97, 2009.

Ros, R.; Eckel, R.; Bartels, F.; Sischka, A.; Baumgarth, B.; Wilking, S. D., Pühler, A.; Sewald, N.; Becker, A. \& Anselmetti, D. Single molecule force spectroscopy on ligand-DNA complexes: from molecular binding mechanisms to biosensor applications. J. Biotechnol., 112:5-12, 2004.

Rosenthal, E.; Poizot-Martin, I.; Saint-Marc, T.; Spano, J. P. \& Cacoub, P. Phase IV study of liposomal daunorubicin (DaunoXome) in AIDS-related Kaposi sarcoma. Am. J. Clin. Oncol., 25:57-9, 2002.

Roses, A. D. Pharmacogenetics in drug discovery and development: a translational perspective. Nat. Rev. Drug Discov., 7:807-17, 2008.

Rotsch, C. \& Radmacher, M. Drug-induced changes of cytoskeletal structure and mechanics in fibroblasts: an atomic force microscopy study. Biophys. J., 78:520-35, 2000.

Rusmini, F.; Zhong, Z. \& Feijen, J. Protein immobilization strategies for protein biochips. Biomacromolecules, 8:1775-89, 2007.

Sakamoto, S. ; Kabe, Y.; Hatakeyama, M.; Yamaguchi, Y. \& Handa, H. Development and application of highperformance affinity beads: toward chemical biology anddrug discovery. Chem. Rec., 9:66-85, 2009.

Salvador-Morales, C.; Zhang, L.; Langer, R. \& Farokhzad, O. C. Immunocompatibility properties of lipid-polymer hybrid nanoparticles with heterogeneous surface functional groups. Biomaterials, 30:2231-40, 2009.

Schonherr, H.; Rozkiewicz, D. I. \& Vancso, G. J. Atomic force microscopy assisted immobilization of lipid vesicles. Langmuir, 20:7308-12, 2004.

Sharma, D.; Perisic, O.; Peng, Q.; Cao, Y.; Lam, C.; Lu, H. \& Li, H. Single-molecule force spectroscopy reveals a mechanically stable protein fold and the rational tuning of its mechanical stability. Proc. Natl. Acad. Sci. US A, 104:9278-83, 2007.

Shelley, C. S.; Farokhzad, O. C. \& Arnaout, M. A. Identification of cell-specific and developmentally regulated nuclear factors that direct myeloid and lymphoid expression of the CD11a gene. Proc. Nat/. Acad. Sci. U S A, 90:5364-8, 1993.

Shi, X.; Xu, L.; Yu, J. \& Fang, X. Study of inhibition effect of Herceptin on interaction between Heregulin and ErbB Receptors HER3/HER2 by single-molecule force spectroscopy. Exp. Cell Res., 315(16):284755, 2009.
Shi, X.; Wang, S. H.; Van Antwerp, M. E.; Chen, X. \& Baker, J. R. Jr. Targeting and detecting cancer cells using spontaneously formed multifunctional dendrimer-stabilized gold nanoparticles. Analyst, 134:1373-9, 2009.

Shi, Y. \& Huang, G. Recent developments of biodegradable and biocompatible materials based micro/nanoparticles for delivering macromolecular therapeutics. Crit. Rev. Ther. Drug Carrier Syst., 26:29-84, 2009.

Shin, H. C.; Alani, A. W.; Rao, D. A.; Rockich, N. C. \& Kwon, G. S. Multi-drug loaded polymeric micelles for simultaneous delivery of poorly soluble anticancer drugs. J. Control Release, 140:294-300, 2009.

Sinensky, A. K. \& Belcher, A. M. Label-free and highresolution protein/DNA nanoarray analysis using Kelvin probe force microscopy. Nat. Nanotechnol., 2:653-9, 2007.

Solin, S. A. Magnetic field nanosensors. Sci. Am., 291:70-7, 2004

Soundararajan, S.; Chen, W.; Spicer, E. K.; CourtenayLuck, N. \& Fernandes, D. J. The nucleolin targeting aptamer AS1411 destabilizes Bcl-2 messenger RNA in human breast cancer cells. Cancer Res., 68:235865, 2008.

Staple, D. B.; Payne, S. H.; Reddin, A. L. \& Kreuzer, H. J. Model for stretching and unfolding the giant multidomain muscle protein using single-molecule force spectroscopy. Phys. Rev. Lett., 101:248301, 2008.

Tamerler, C.; Oren, E. E.; Duman, M.; Venkatasubramanian, E. \& Sarikaya, M. Adsorption kinetics of an engineered gold binding Peptide by surface plasmon resonance spectroscopy and a quartz crystal microbalance. Langmuir, 22:7712$8,2006$.

Tang, N.; Du, G.; Wang, N.; Liu, C.; Hang, H. \& Liang, W. Improving penetration in tumors with nanoassemblies of phospholipids and doxorubicin. J. Natl. Cancer Inst., 99:1004-15, 2007.

Tekade, A. R. \& Gattani, S. G. Development and evaluation of pulsatile drug delivery system using novel polymer. Pharm. Dev. Technol., 14(4):3807, 2009

Thauvin, C.; Rickling, S.; Schultz, P., Célia, H.; Meunier, S. \& Mioskowski, C. Carbon nanotubes as templates for polymerized lipid assemblies. Nat. Nanotechnol., 3:743-8, 2008.

Torchilin, V. P. Nanocarriers. Pharm. Res., 24:2333-4, 2007. 
Tsuji, J. S.; Maynard, A. D.; Howard, P. C.; James, J. T.; Lam, C. W.; Warheit, D. B. \& Santamaria, A. B. Research strategies for safety evaluation of nanomaterials, part IV: risk assessment of nanoparticles. Toxicol. Sci., 89:42-50, 2006.

Tsukada, Y.; Hara, K.; Bando, Y.; Huang, C. C.; Kousaka, Y.; Kawashima, Y.; Morishita, R. \& Tsujimoto, H. Particle size control of poly(dl-lactide-co-glycolide) nanospheres for sterile applications. Int. J. Pharm., 370:196-201, 2009.

Uhrich, K. E.; Cannizzaro, S. M.; Langer, R. S. \& Shakesheff, K. M. Polymeric systems for controlled drug release. Chem. Rev., 99:3181-98, 1999.

Vo-Dinh, T. \& Kasili, P. Fiber-optic nanosensors for single-cell monitoring. Anal. Bioanal. Chem., 382:918$25,2005$.

Wagner, V.; Dullaart, A.; Bock, A. K. \& Zweck, A. The emerging nanomedicine landscape. Nat. Biotechnol., 24:1211-7, 2006.

Walgren, J. L. \& Thompson, D. C. Application of proteomic technologies in the drug development process. Toxicol. Lett., 149:377-85, 2004.

Wang, W. U.; Chen, C.; Lin, K. H.; Fang, Y. \& Lieber, C. M. Label-free detection of small-molecule-protein interactions by using nanowire nanosensors. Proc. Natl. Acad. Sci. U S A, 102:3208-12, 2005.

Wang, Y. C.; Liu, X. Q.; Sun, T. M.; Xiong, M. H. \& Wang, J. Functionalized micelles from block copolymer of polyphosphoester and poly(epsilon-caprolactone) for receptor-mediated drug delivery. J. Control Release, 128:32-40, 2008.

Wingren, C. \& Borrebaeck, C. A. Progress in miniaturization of protein arrays--a step closer to high-density nanoarrays. Drug Discov. Today, 12:813-9, 2007.

Xu, P.; Gullotti, E.; Tong, L.; Highley, C. B.; Errabelli, D. R.; Hasan, T.; Cheng, J. X.; Kohane, D. S. \& Yeo, Y. Intracellular drug delivery by poly(lactic-co-glycolic acid) nanoparticles, revisited. Mol. Pharm., 6:190201, 2009.

Xuan, X. Ion separation in nanofluidics. Electrophoresis 29:3737-43 (2008).

Yih, T. C. \& Moudgil, V. K. Nanotechnology comes of age to trigger the third industrial revolution. Nanomedicine, 3:245, 2007.

Zhao, D. L.; Zhang, H. L.; Zeng, X. W.; Xia, Q. S. \& Tang, J. T. Inductive heat property of Fe304/polymer composite nanoparticles in an ac magnetic field for localized hyperthermia. Biomed. Mater., 1:198-201, 2006.
Zhang, H. \& Gao, S. Temozolomide/PLGA microparticles and antitumor activity against glioma C6 cancer cells in vitro. Int. J. Pharm., 329:122-8, 2007.

Zhang, C. Y.; Yeh, H. C.; Kuroki, M. T. \& Wang, T. H. Single-quantum-dot-based DNA nanosensor. Nat. Mater., 4:826-31, 2005.

Zhuo, R. X.; Du, B. \& Lu, Z. R. In vitro release of 5fluorouracil with cyclic core dendritic polymer. J. Control Release, 57:249-57, 1999.

Correspondence to:

Cristian Vilos, PhD.

Center for Integrative Medicine

and Innovative Science (CIMIS)

Universidad Andres Bello

Facultad de Medicina

Echaurren 183

Santiago

CHILE

Tel: +56228370071

Email: cristian.vilos@unab.cl

Received: 10-12-2013

Accepted: 09-01-2014 